portant in situ assessment of radiogenic components. Future deployments would be equally successful with the tool mounted on the basket, given the observed sensitivity. We are continuing modifications of the corer to provide more versatility in coring targets. Anticipated modifications include introduc tion of a fluid circulation system for removal of cuttings, modification of the drill to allow multiple cores per dive, addition of a swivel to permit vertical drilling, and addition of heat tabs to monitor temperatures of fluid at the cutting head. The stratigraphic control provided by the drill cores will be exploited for mineralogical, chemical, and stable and radiogenic isotopic examination. Future studies may include using the drill holes to sample fluids from the base of the largest edifices or to do in situ experiments on the temperature variations across the walls of the sulfide edifices

\section{Scientific Party}

Members of the scientific party were Debra S. Stakes, Willard S. Moore, Sara Redding, Joseph Smoak, and Judy Minnich, University of South Carolina, Columbia; Meg Tivey, Woods Hole Oceanographic Institution, Woods Hole, Mass.; Mark Hannington, Geological Survey of Canada; John Edmond and Henriette Edmonds, Massachusetts Institute of Technology, Cambridge; James F. Todd, NOAA, Silver Spring, Md.; Joe Cychosz, Purdue University, West Lafayette, Ind; Najid Hussain, University of Delaware, Newark; Kevin Mandernack, Scripps Institution of Oceanography, La Jolla, Calif.; and Marsha Bollinger, Wintrop College, Rock Hill, S.C.

\section{Acknowledgments}

The special consultant for development of the drill is Gary Rajcula, former ALVIN p lot. The cruise and the development of the drill and gamma detector were supported by the Ocean Science Division, National Sci ence Foundation, OCE90-19300.

\section{References}

Delaney, J. R., R. E. Mcduff, and J. E. Lupton, Hydrothermal fluid temperatures of $400^{\circ} \mathrm{C}$ on the Endeavour Segment, northern Juan de Fuca (abstract), EOs Trans. AGU, 65, 973, 1984

Delaney, J. R., M. D. Lilley, R. E. McDuff and I A Baross, Standing pools of $350^{\circ} \mathrm{C}$ fluid and large seafloor sulfide structures (abstract), Eos Trans. AGU, 69, 1497, 1988

Delaney, J. R., V. Robigou, R. E. Mcduff, and M. K Tivey, Detailed geologic relationships of a vigorous hydrothermal system: The Endeavour Vent Field, Northern Juan de Fuca Ridge, J. Geophys. Res., in press, 1992.

Kappel, E. S., and W. B. F. Ryan, Volcanic episodicity and non-steady rift valley along Northeast Pacific speading centers: Evidence from SeamaRC II, J. Geophys. Res., 9I, 13,925, 1986 Mathieu, G. G., P. E. Biscaye, R. A. Lupton, and D. E. Hammond, System for measurement of ${ }^{222} \mathrm{Rn}$ at low levels in natural waters, Health Phys., 55, 989,1988

Robigou, V., J. R. Delaney, and R. E. McDuff, High precision, high-resolution map of a vigorous hydrothermal vent field (abstract), Eos Trans AGU 71, 1610,1990 .
Robigou, V., and J. R. Delaney, Comparison of hydrothermal vent fields, Endeavour Segment, Juan de Fuca Ridge (abstract), Eos Trans. AGU, 72 $232,1991$.

Stakes, D. S., and W. S. Moore, Evolution of hydro thermal activity on the Endeavour-Juan de Fuca
Ridges: Observations, mineral ages, and Ra isotope ratios, J. Geophys. Res., 96, 21,739, 1991.

Tivey, M. K., and J. R. Delaney, Growth of large sulfide structures on the Endeavour Segment of the Juan de Fuca Ridge, Earth Planet. Sci. Lett $77,309,1986$.

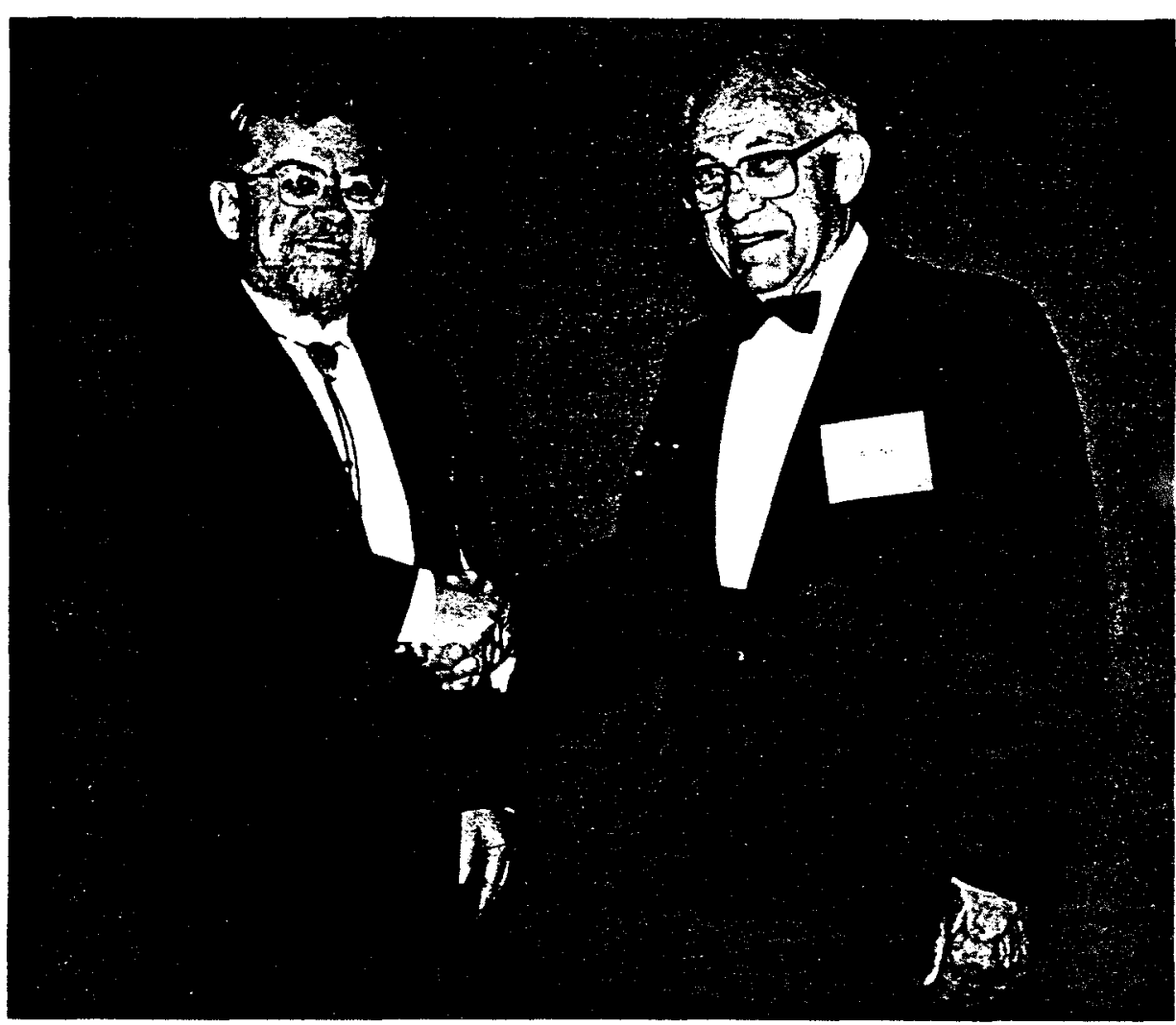

Alfred O. C. Nier (right) being congratulated by Don L. Anderson.

\title{
Nier Receives 1992 Bowie Medal
}

\section{PAGES 273-274}

Alfred O. C. Nier was awarded the 1992 William Bowie Medal for outstanding contributions to fundamental geophysics and unselfish cooperation in research. The Bowie Medal, AGU's most distinguished honor, was presented to Nier on May 13 at the annual Spring Meeting Honors Ceremony in Montreal, Quebec, Canada.

The award citation, delivered by Don $\mathrm{L}$. Anderson, and Nier's response are presented below.

\section{Citation}

\section{Although we are mere sojourners} on the surface of the planet.

chained to a mere point in space enduring but for a moment of time.

the human mind is not only enabled to number worlds

beyond the unassisted ken of mortal eye,

but to trace the events of indefinite ages before the creation of our race, and is not even with held from penetrating into the dark secrets of the ocean, or the interior of the solid globe, free, like the spiril which the poet described as animating the universe. Sir Charles Lyell

Principles of Geology (1830)

"Thus, Sir Charles Lyell, the founder of geology, unwittingly described our Bowie Medalist. From the smallest speck of space dust to the tenuous envelope of a crimson point in the sky, he has taken the measure of them all.

'II's a Wonderful Life' is how one would describe Al Nier and how he would, undoubtedly, describe his own view of things. It is also a Hollywood film directed by Frank Capra which explores the thesis of what the world would be like without one Jimmy Stewart. It is easy for me to imagine a world without Jimmy Stewart but it is not easy to imagine a world without Al Nier. But let us try. What would our world be like without Professor Alfred O. C. Nier?

"First of all, Professor Nier discovered potassium 40 and uranium 235. Therefore, without Professor Nier there would be no geochronology. We would believe that our world was born in 4004 B.C. and there 
would certainly be no Brent Dalrymple sitting on this stage.

"Geology departments would not be awash in mass spectrometers.

"No one would know about cosmogonic or primordial noble gases.

"We would not be talking about nanograms and picomoles, fancy words for almost nothing; hardly bigger than the twinkle in Professor Nier's eye.

"There would be no cosmochronology.

"There would be no isotope geochemistry-certainly no ${ }^{3} \mathrm{He}, \mathrm{C}$, or $\mathrm{O}$ data of merit.

"The section of Volcanology, Geochemis try, and Petrology of the AGU would have little to say at these meetings.

"The Geomagnetism section would not understand that their magnetic stripes are a tape recorder.

"The Tectonophysics section would not know about age progressions and hotspot tracks.

"Chemistry would not be a part of the Planetology or Atmospheric Sciences sections.

"On the other hand, there would be no isolope geochemists!

"The world would be quite a different place

\section{If fate had decided that Professor Nier should be a banker \\ not a gadgeteer \\ or like Frank Capra \\ an unemployed Caltech engineer Anon (1992)}

"Al Nier can be considered to be the founder of isotope geology, geochronology and isotope geochemistry. He wrote great papers in 1939 on U-Th-Pb dating in Physical Reviews. The potassium-argon, the lead-lead and the uranium-lead chronometers all evolved from his measurements on his instruments. He and Arthur Holmes set the stage for determination of the ages of our worlds; the potassium-argon ages, the leadlead ages, the uranium-lead ages, all ages.

"Many mass spectrometers in the world today, and scattered about space, were built by Al Nier or are direct descendents of his instruments of the 1940s and 1950s. Many in use today were made in the University of Minnesola machine shop. His development of miniaturized spectrometers opened up the field of near and deep space research, including the atmosphere and surface of Mars.

"He expanded the periodic table. His measurements contributed to the data base which sustained the theory of element synthesis in stars.

"It would be possible to go on about the past like this for hours. The amazing thing about Professor Nier's wonderful life, however, is the present and the future. He is currently investigating helium and neon concentrations in microgram-to-nanogram-mass individual particles of extraterrestrial dust collected in the stratosphere and from deep ocean sediments. To do so he has developed exquisite new microanalytic techniques for use on vanishing small samples of this cosmic flux." Now in a real tour-de-force he is doing stepwise heating on these tiny samples, to "see the world in a grain of sand."

The works of the Magician of the Beautiful are not like ours

and in the least fragment His artistry is no less present than in the stars.

We may enter the infinite through the minute

no less than through contemplation of the vast

\section{Æ (aka George William Russell}

1867- 1935)

"Al refers to himself as 'more of a gadgeteer than most physicists.' But Dr. Nier was never only a gadgeteer because his painstaking improvements in instrumentation and technique are always aimed at specific scientific questions or a further undérstanding of processes in Nature. Dr. Nier has used mass spectrometers to find answers to a very broad range of scientific questions. These reach from atomic physics, to medicine, biology, and geology to atmospheric chemistry and planetary atmospheres. He has built the smallest and the largest instruments and has populated the solar system with them. He studies spectrums of spheres. He brings the smallest spheres to Minnesota and sends a piece of Minnesota to the bigger spheres.

"Dr. Nier is a truly distinguished experi mental physicist who has made majestic contributions to the understanding of our world and our life. Our profession is richer because of his work and his presence. It may be difficult, if not impossible, to name a scientist whose work has had, and still has, as large an impact on as many scientific dis ciplines, and for such a long period, as that of Professor Nier.

"All in all, Professor Alfred O. C. Nier is a broad-minded and unselfish scientist, a diplomatic yet decisive leader, and a gentle and likeable person. He is eager to help others and epitomizes the Bowie Medal's 'unselfish cooperation in research.' His colleagues are awed by his experimental prowess and his wonderful collegial manner of openly sharing all data, ideas, and speculations. It is easy to understand why this wonderful, softspoken scientist is so highly revered by all who come in contact with him. It has been said that some wise people see further than others because they stand on the shoulders of giants. In the case of Al Nier we can all see further because generations of giants have stood on his shoulders. Many medalists have stood on this stage and acknowledged their indebtedness to Al Nier. The AGU and the entire geophysical community share in this debt.

'Yes, It is a wonderful life,' the life of Professor Alfred O. C. Nier, a founder of modern geochemistry and cosmochemistry and this year's Bowie Medalist. We can call him 'the man of the ages."'-Don L. Anderson

*And what are these fuxions? The velocities of evanescent increments. And what are these same evanescent increments? They are neither finite quantities, nor quantities infnitely small, nor yet nothing. May we not call them ghosts of departed quantities?

The Analyst (1734)

\section{Response}

"Many thanks for the kind remarks, Don. While it is true I have worked in a number of areas, I really should not get credit for not having outgrown the limited attention span which one has when one is 2 years old Your introduction also reminded me of the story of the man who was telling his young son about his accomplishments in the Great War. When he finished, the child asked, 'But Dad, what did all the other soldiers do?'

"I need not tell this group how interesting geophysics is. There seems to be something for everyone. One may even find oneself in the field without realizing it has taken place. I think I represent such a happening. This seems to be in contrast to Don Anderson's history. As I read between the lines of Professor Raleigh's citation when Don was awarded the Bowie Medal last year, I gained the impression that as a baby Don may have been given a seismograph as a rattle to shake. I can prove I was not given a mass spectrometer at that age; such instruments did not exist in 1911 !

"It has been interesting to think back about events that led me to become at least a part-time geophysicist. After obtaining my bachelor's and masters degrees in electrical engineering at the University of Minnesota in the early 1930 s, I continued my graduate studies in physics. After several nonproductive starts on thesis subjects, I decided to follow in the footsteps of students who had preceded me, studying the ionization and dissociation of gases undergoing electron impact. The mass spectrometer I constructed incorporated important features I inherited from my predecessors plus some minor improvements I was able to make. The net result was an instrument which was more sen sitive and stable than others in existence. However, my advisor, the late John T. Tate, whose students had made enviable contribu tions to the field, seemed to be losing interest in the area and was pushing the develop. ment of nuclear physics which was just emerging as an exciting new field. It seemed prudent for me, a lowly graduate student, to follow suit and use my mass spectrometer for something relating to nuclear physics. This led to the discovery of $40 \mathrm{~K}$, the radioactive isotope later shown to be useful for making geological age measurements.

"When I received my Ph.D. degree, I had the good fortune to be awarded a National Research Council fellowship and accepted Professor Kenneth Bainbridge's invitation to come to the Harvard Physics Department. Bainbridge helped me design an improved mass spectrometer which could make precise isotopic ratio measurements throughout the entire atomic table. Professor Gregory Baxter, in the Chemistry Department, placed at my disposal the entire collection of common and radiogenic lead samples on which he and his predecessor, T. W. Richards, had made their historic atomic weight determinations, and with the help and encouragement of others, I was launched on a program of making geologic age measurements.

"Later, when I returned to Minnesota as a faculty member, there were other interests, but research relating to geophysics contin- 
ued, including participation in the 1970s in the Viking Mission to Mars, through which I met Don and many other scientists and engineers who became close friends, and for whom I gained enormous respect. It was one of my most rewarding experiences.

"In closing, I should like to acknowledge the help of the many other individuals along the way who directly or indirectly played a part in my being here tonight. My parents were immigrants in the last century who had very limited educational opportunities, but wanted better for their children. There were the teachers and professors who provided encouragement, the students who played an indispensable role in much of my research, and the colleagues at my own and other institutions who provided inspiration and help when it was needed. And finally, the American Geophysical Union, which has made the present event possible." -Alfred O. C. Nier

\section{International Meeting Airs Ozone Studies}

\section{The Troposphere: New Hot Spot for Ozone Research}

\section{PAGES 273, 275}

The dramatic discovery of the stratospheric ozone hole has eclipsed attention to ozone increases in the troposphere, the lowest layer of the atmosphere beginning at the Earth's surface. But tropospheric ozone got equal billing with the stratosphere at a recent international symposium, suggesting that tropospheric issues have come into their own.

"Only in the past decade or so has tropospheric ozone become an important scientific concern," said Henry Reichle of Langley Research Center. Historically, the Quadrennial Ozone Symposium, begun in 1927, dealt only with the stratosphere. But tropospheric studies shared the limelight at this year's meeting, held June 4-13 at the University of Virginia in Charlottesville. "Now we understand that tropospheric ozone can have an impact on a larger scale, not just locally," Reichle said.

Satellite images now show that tropospheric pollution produced by cities in the Northern Hemisphere is causing damage on a regional, possibly even global scale. The Northern Hemisphere simply may not have any regions of clean air left.

Even in the Southern Hemisphere, a mys terious "hot spot" of high ozone has been discovered in the troposphere over the southern Atlantic Ocean, a region remote from industrialized areas. The phenomenon has been wryly dubbed "our tropospheric answer to the ozone hole" by NASA Goddard Space Flight Center researcher Anne Thompson.

Only about $10-20 \%$ of all ozone resides in the troposphere, which is divided into a turbulent "mixed layer" above the Earth's surface, and the less-polluted free troposphere atop that. Tropospheric ozone, at least in the Northern Hemisphere, has been increasing. European measurements record a five-fold increase since a century ago. Over the past decade, Europe has recorded a $10 \%$ rise, and the United States has also noted an increase.

But are tropospheric ozone levels rising across the globe? The best ozone data-as for weather and climate measurements gen- erally-cover the northern mid-latitudes. "There are few measurements in the Southern Hemisphere, and the troposphere tends to be a highly variable place," pointed out $\mathrm{V}$. Ramaswamy of the Geophysical Fluid Dynamics Laboratory. More stations around the globe would be needed to truly pin down tropospheric trends, he said.

One new observation is that ozone does seem to increase substantially in the free troposphere during the spring, within a large band across the Northern Hemisphere. Stuart Penkett of the University of East Anglia theorizes that at high northern latitudes in winter the tightly restricted air circulation "stores" or limits the circulation of pollutants. As polar circulation breaks down in spring, released pollutants surge southward, accounting for the increase.

The Southern Hemisphere has its own worrisome mega-feature in the troposphere: that striking and persistent "hot spot" of elevated ozone out over the southern Atlantic Ocean. The feature shows up during the austral spring in a region actually thought a dec ade ago to be low in ozone. This ozone maximum, which was discovered by Jack Fishman of Langley Research Center using data from the Total Ozone Mapping Spectrometer (TOMS) and the Stratospheric Aerosol and Gas Experiment (SAGE) instrument and confirmed by balloon measurements, has spawned a new area of research. Fishman and others believe that the location of this hot spot between two regions of biomass burning South America and southern Africa-is no coincidence. Others, however, argue that this ozone-laden air is being transported from elsewhere, or even being created naturally by local emissions from soil and biota.

"The debate is just opening up," said Thompson. "We are now where the stratospheric ozone researchers were 7 years ago, just as the ozone hole began to be identified." New campaigns beginning this summer, involving 13 countries, will probe the chemical mechanisms responsible for this ozone enhancement, assess the relative con- tributions from Africa and South America, and try to gauge whether 1992 is a typical year for this phenomenon.

Both the hot spot and the spring maximum are the latest examples of the longstanding debate about the origins of tropospheric ozone. "The problem has always been, where does tropospheric ozone come from?" said Penkett. In the past, the theory was that it all simply leaked down after forming in the stratosphere. In the early 1970s, Paul Crutzen, now of the Max Planck Institute in Mainz, Germany, proposed that a series of chemical reactions could produce ozone rapidly and on a wide scale - not just locally as urban smog. City air, laden with the nitrogen oxides that regulate the amount of tropospheric ozone, could blow over "clean" rural areas and enable ozone production there. A compound called peroxy acetyl nitrate (PAN), produced in the troposphere but not in the stratosphere, can be used as a marker to verify a tropospheric source.

Tropospheric ozone's impact on climate is now being probed. The balance sheet for ozone's overall climatic effect is complicated. Recent studies by Ramaswamy and others suggest that chlorofluorocarbons, a greenhouse gas, will warm the troposphere, but their destruction of ozone in the stratosphere will at the same time cool the troposphere. The upshot is that the two effects may offset each other.

But the increase in tropospheric ozone will also tend to cause greenhouse warming, said Ramaswamy, who is using the most recent observations available to quantify the impact of increasing tropospheric ozone on climate. He has taken levels of tropospheric ozone from one of the most polluted stations, Hohenpeissenberg in Germany, and extrapolated them across the northern midlatitudes. His model suggests a climate warming approaching the magnitude of, but of course opposite to, the cooling caused by stratospheric ozone destruction. He cautioned, however, that finer-tuned predictions require better observations, particularly from the upper troposphere.

As for the future, Crutzen expects research to focus increasingly on tropospheric ozone in the tropics and developing countries, because of the fundamental changes sweeping these regions-population increases, industrialization, and biomass burning. "We can expect large changes in the overall chemistry of the atmosphere in the future," he said. - Lynn Teo Simarski

\section{Public, Experts Join at Town Meeting}

\section{PAGE 275}

About 80 citizens concerned with the threat of ozone depletion attended a public meeting on June 9 in Charlottesville, Va., to discuss the issue with a panel of six leading ozone experts. Held in conjunction with the Quadrennial Ozone Symposium, the town meeting was videotaped for airing on public broadcast stations this fall. The meeting was aimed at nonexperts, to "get the word out" 